Colloque C2, suppl. au Journal de Physique II, Vol. 1, septembre 1991

\title{
MOCVD OF TANTALUM PENTOXIDE FOR LARGE-AREA ULST CIRCUIT WAFERS
}

\author{
W. KERN, A. CHEN and N. SANDLER \\ Lam Research Corporation, 9250 Trade Place, San Diego, \\ CA 92126, U.S.A
}

\begin{abstract}
Ta}_{2} \mathrm{O}_{5}$ films of 10-150 nm thickness were prepared by oxygen-assisted pyrolytic LPCVD at $450-490^{\circ} \mathrm{C}$ from tantalum penta ethoxide and $\mathrm{O}_{2}$ with $\mathrm{N}_{2}$ diluent. Silicon wafers $150 \mathrm{~mm}$ in diameter were used as substrates with a novel LPCVD reactor. The films were annealed in dry $\mathrm{O}_{2}$ at $700-800^{\circ} \mathrm{C}$. Compositional, structural, and electrical evaluations demonstrate that these uniform, pure, and conformal $\mathrm{Ta}_{2} \mathrm{O}_{5}$ films are a viable alternative dielectric suitable for advanced megabit DRAM applications.
\end{abstract}

\section{Introduction}

Current types of silicon MOS memory devices use $\mathrm{SiO}_{2}$ or $\mathrm{Si}_{3} \mathrm{~N}_{4} / \mathrm{SiO}_{2}$ thin films as capacitor dielectrics. Since future generation ULSI circuits with decreased feature sizes would require excessively thin films for these low-dielectric constant materials, dielectrics with much higher dielectric constants are a logical alternative. The properties of tantalum pentoxide, $\mathrm{Ta}_{2} \mathrm{O}_{5}$, are especially attractive for this application.

The formation of $\mathrm{Ta}_{2} \mathrm{O}_{5}$ films has been studied extensively over the years by anodic oxidation [1] and thermal oxidation [2] of tantalum films, by rf sputtering [3,4], and by chemical vapor deposition [5-8]. The formation of $\mathrm{Ta}_{2} \mathrm{O}_{5}$ (and other high-dielectric constant films) from metal halides and organometallic reactants by CVD has been reviewed recently [5]. Previous CVD studies based on the metalorganic compound tantalum penta ethoxide, $\mathrm{Ta}\left(\mathrm{OC}_{2} \mathrm{H}_{5}\right)_{5}$, as the starting reactant have led to encouraging results [6-8]. However, as-deposited films did not have sufficiently high dielectric breakdown strength, probably due to carbon contamination from the source reactant, and required annealing at $800-850^{\circ} \mathrm{C}$ in $\mathrm{O}_{2}$ or $\mathrm{O}_{3}$. Furthermore, in these feasibility studies, film deposition parameters were not optimized for the large-area substrates required in ULSI fabrication.

In this paper, we describe the formation of $\mathrm{Ta}_{2} \mathrm{O}_{5}$ films by thermal LPCVD in a novel, single-pass, laminar flow reactor from $\mathrm{Ta}\left(\mathrm{OC}_{2} \mathrm{H}_{5}\right)_{5}$ as the source material. The keys to obtaining excellent uniformity of the films over large-area substrates are control of residence time, precise temperature control, and optimal oxygen-to-Ta source ratio. 


\section{Experimental}

The tantalum penta ethoxide source (Cerac) was $99.999 \%$ pure and was used without further purification. The vaporized source liquid was carried by nitrogen and mixed with oxygen just before being introduced into the reaction chamber. Both $\mathrm{O}_{2}$ and $\mathrm{N}_{2}$ must be ultradry and ultrapure. Typical deposition and annealing conditions are listed in Table 1. Both planar and trench etched $150-\mathrm{mm}$ diameter silicon wafers were used as test substrates.

The reactor is an automated, thermal LPCVD disk system from Lam Research Corporation. It is designed for precise control of gas flow dynamics, reactant concentration across the wafer load, process temperature, and system pressure. Gas flow is laminar, single-pass and cross-flow. Gas-phase nucleation of particles is minimized since no gas recirculation occurs.

The films have been characterized by $\mathrm{x}$-ray photoelectron spectroscopy (XPS, ESCA), $\mathrm{x}$-ray diffraction (XRD), Rutherford backscatter spectroscopy (RBS), and scanning electron microscopy (SEM). The film thickness and refractive index were measured by ellipsometry. Particle densities were scanned with a standard particle counting instrument. Electrical characteristics were measured from metal-oxidesemiconductor (MOS) capacitors fabricated from the $\mathrm{Ta}_{2} \mathrm{O}_{5}$ films on $\mathrm{Si}$ with $\mathrm{Al}$ gate electrodes of $1 \mathrm{~mm}$ in diameter. A post-metallization anneal of $30 \mathrm{~min}$ in forming gas at $450^{\circ} \mathrm{C}$ was applied. The MOS capacitors were then measured for dc current-voltage $(\mathrm{I}-\mathrm{V})$, high-frequency $(1 \mathrm{MHz})$ capacitance-voltage (C-V) characteristics, and leakage current density $v s$. gate voltage properties.

\section{Results and Discussion}

The rate of film deposition as a function of substrate temperature is shown in Fig. 1 for the working range of $450-490^{\circ} \mathrm{C}$. The Arrhenius relation over this narrow, optimal temperature interval indicates an energy of activation of $31.5 \mathrm{kcal} / \mathrm{mol}$. The uniformity of film thickness over $150-\mathrm{mm}$ diameter substrate wafers is $\leq 2 \%$ at 1 s for films of approximately $30-\mathrm{nm}$ thickness (within wafer and wafer-to-wafer). Average added particle density (calculated from 100 runs) is less than $0.2 / \mathrm{cm}^{2}$ for particle sizes of $0.3 \mu \mathrm{m}$ and larger (with $6-\mathrm{mm}$ edge exclusion). Since the film deposition under the conditions stated in this low pressure reactor are surface-controlled, one can expect excellent conformality. Figure 2 demonstrates that this is indeed the case. The SEM cross-section micrograph with $7.2 \mu \mathrm{m}$ deep trenches of $0.78-\mu \mathrm{m}$ center width shows a uniform $0.15 \mu \mathrm{m}$ thick conformal film of $\mathrm{Ta}_{2} \mathrm{O}_{5}$ on $\mathrm{Si}$.

The ESCA survey spectrum in Fig. 3 is that for a typical $\mathrm{Ta}_{2} \mathrm{O}_{5}$ film deposited at $470^{\circ} \mathrm{C}$ followed by 2 min of sputter etching with $\mathrm{Ar}^{+}$ions at $4 \mathrm{KV}$ energy to remove surface impurities. No detectable carbon or other impurities are contained in the interior of the film. The Ta:O ratio derived from ESCA data is 1:2.6. The as-deposited films are amorphous and relatively dense, with an index of refraction of 2.19 and a low etch rate of $8.0 \mathrm{~nm} / \mathrm{min}$ in $25 \%$ aqueous $\mathrm{HF}$ solution at room temperature.

An $8.0 \mathrm{~nm}$ thick mixed region of $\mathrm{Ta}, \mathrm{Si}$, and $\mathrm{O}$ was detected in the RBS spectrum of Fig. 4. The presence of a thin layer of $\mathrm{SiO}_{2}$ below the $\mathrm{Ta}_{2} \mathrm{O}_{5}$ film was reported previously and is thought to grow mainly in the oxygen atmosphere of the CVD 
reactor immediately prior to deposition of the $\mathrm{Ta}_{2} \mathrm{O}_{5}$ film, or it could be due to the oxidation of $\mathrm{Si}$ by $\mathrm{Ta}_{2} \mathrm{O}_{5}$ at the interface [6-8].

Figure 5 shows the compound index of refraction as a function of film thickness for $\mathrm{Ta}_{2} \mathrm{O}_{5}$ layers deposited at $470^{\circ} \mathrm{C}$. A similar plot of effective dielectric constant versus film thickness for a large number of samples from different process runs is presented in Fig. 6. Calculated curves based on $2.0 \mathrm{~nm}$ and $3.5 \mathrm{~nm}$ of $\mathrm{SiO}_{2}$ interface layers have been included to show their effects on the $\mathrm{Ta}_{2} \mathrm{O}_{5}$ dielectric constant values. The above data were obtained with an $\mathrm{Hg}$ probe electrode. The current-voltage (I-V) and capacitance-voltage $(\mathrm{C}-\mathrm{V})$ characteristics of thin $\mathrm{Ta}_{2} \mathrm{O}_{5}$ films $(13.0 \mathrm{~nm})$ had a C/Cox of 0.95 at zero flatband voltage and an actual dielectric strength of $2.8 \mathrm{MV} / \mathrm{cm}$ at $1 \mathrm{E}-6 \mathrm{~A}$.

Figure 7 shows a Schottky plot of the leakage current density for a MOS capacitor fabricated with evaporated aluminum gate electrodes. The film was annealed at $800^{\circ} \mathrm{C}$ for $10 \mathrm{~min}$ in dry $\mathrm{O}_{2}$ prior to electrode formation. The leakage current density is lower for annealed films compared with those that are as-deposited. The leakage current density appears to be lower for films deposited in this system than those from cold wall reactors. We believe this is due to higher oxygen incorporation in the asdeposited films using the single-pass cross-flow LPCVD reactor. Detailed experiments are underway to quantify these effects.

Annealing studies were performed to investigate the effects of post-deposition heat treatment on electrical properties of the films that may occur due to changes in their structure. As-deposited $\mathrm{Ta}_{2} \mathrm{O}_{5}$ films were found to be amorphous by XRD. It is known that annealing causes crystallization of the films to $\mathrm{B}_{-} \mathrm{Ta}_{2} \mathrm{O}_{5}$ [8]. The dielectric breakdown strength was observed to increase with higher anneal temperature. Furthermore, the feasibility was demonstrated for dry-etching vertical profile patterns in photoresist-masked $\mathrm{Ta}_{2} \mathrm{O}_{5}$ layers by $\mathrm{CF}_{4} / \mathrm{CHF}_{3} / \mathrm{Ar}$ chemistry in a commercial etcher (Rainbow 4500, [9]).

We have also successfully deposited thin films of niobium pentoxide by oxygenassisted pyrolysis of niobium penta ethoxide, $\mathrm{Nb}\left(\mathrm{OC}_{2} \mathrm{H}_{5}\right)_{5}$, analogous to the conditions described for $\mathrm{Ta}_{2} \mathrm{O}_{5}$.

\section{Conclusions}

A process has been presented for depositing films of $\mathrm{Ta}_{2} \mathrm{O}_{5}$ over large-area substrates. Optimum temperature under LPCVD conditions is $470^{\circ} \mathrm{C}$. These films are amorphous as-deposited and yield, for our samples, the highest dielectric breakdown strength of $>4.0 \mathrm{MV} / \mathrm{cm}$ when annealed at $800^{\circ} \mathrm{C}$ in $\mathrm{O}_{2}$. I-V characteristics of MOS capacitors from typical as-deposited films show low leakage currents and dielectric breakdown fields centered at $2.8 \mathrm{MV} / \mathrm{cm}$. The dielectric constant of the films is about 23 , and thickness uniformity over $150-\mathrm{mm}$ substrate wafers has variations of only $2 \%$ or lower. Particle density is less than 0.2 added $(\geq 0.3-\mu \mathrm{m})$ particles per $\mathrm{cm}^{2}$, and the films are conformal, even in deep and narrow trenches. The keys to uniform deposition over large-area substrates are precise control of residence time, temperature, and $\mathrm{O}_{2}$ incorporation by means of a special LPCVD reactor system designed for optimal film deposition.

Preliminary electrical characterization of the films indicate that they are potentially applicable as a storage capacitor dielectric for advanced 64 megabit DRAM devices. 


\section{Acknowledgments}

The authors wish to thank the following people for their valuable contributions to this work: B. Anderson, D. Freeman, J. Hartman, A. Lane, M. Logan, D. Mytton, E. O'Brien, B. Page, and J. Whitlam.

\section{References}

/1/ OHTA K., YAMADA K., SHIMIZU R., and TARUI Y., IEEE Trans. Electron Devices ED-29, (1982) 368 .

/2/ KATO T., ITOH T., TAGUCHI M., NAKUMURA T., and ISHIKAWA H., Symposium on VLSI Technology, Digest of Technical Papers, IEEE, Piscataway, NJ (1983) 86.

/3/ OEHRLEIN G.S., J. Appl. Phys., 59 (1986) 1587.

/4/ SHINRIKI H., NISHIOKA Y., and MUKAI K., Extended Abstr. of the 19th International Conf. on Solid State Devices and Materials, Business Center for Academic Societies Japan, Tokyo (1987) 215.

/5/ JENSEN K.F. and KERN W., Chpt. IV-1 in THIN FILM PROCESSES II, VOSSEN J.L. and KERN W., editors; Academic Press, New York (1991) 283.

16/ SAITOH M., MORI T., and TAMURA H., International Electron Devices Meeting, Technical Digest No. 32, IEEE, Los Angeles (1986) 680.

/7/ MATSUI M., OKA S., YAMAGISHI K., KUROIWA K., and TARUI Y., Jpn. J. Appl. Phys., 27 (1988) 506.

/8/ ZAIMA S., FIRUTA T., YASUDA Y., and IIDA M., J. Electrochem. Soc., 137 (1990) 1297.

19/ Rainbow 4500 Oxide Etcher, Lam Research Corporation. 
Table 1

\section{Typical Deposition and Annealing Conditions}

\section{Deposition:}

$\mathrm{Ta}\left(\mathrm{OC}_{2} \mathrm{H}_{5}\right)_{5}$ source temperature $\quad 40^{\circ} \mathrm{C}$

Source vaporizer temperature $\quad 200^{\circ} \mathrm{C}$

Delivery tubing temperature $\quad 120-140^{\circ} \mathrm{C}$

Gas flow rate $\left(\mathrm{N}_{2}+\mathrm{O}_{2}\right) \quad 3-6$ slpm

Mole ratio $\mathrm{O}_{2} / \mathrm{Ta}\left(\mathrm{OC}_{2} \mathrm{H}_{5}\right)_{5} \quad 120: 1$

System pressure $\quad 0.4-0.6$ torr

Deposition temperature $\quad 450-490^{\circ} \mathrm{C}$

Deposition time $\quad 5-40 \mathrm{~min}$

Deposition rate $\quad 2.0-10.0 \mathrm{~nm} / \mathrm{min}$

$\mathrm{Ta}_{2} \mathrm{O}_{5}$ film thickness $\quad 10-150 \mathrm{~nm}$

\section{Annealing:}

Oxygen flow rate

$1.0 \mathrm{slpm}$

Substrate temperature

$700-800^{\circ} \mathrm{C}$

System pressure

760 torr

Annealing time

10-30 min 


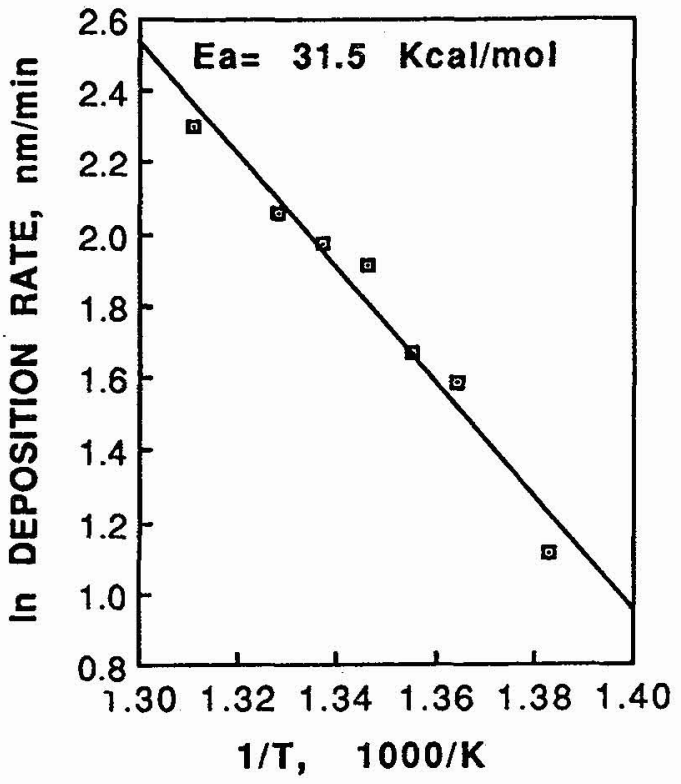

Figure 1. Ta2O5 deposition rate as a function of deposition temperature. The curve shows the process is surface reaction rate limited.

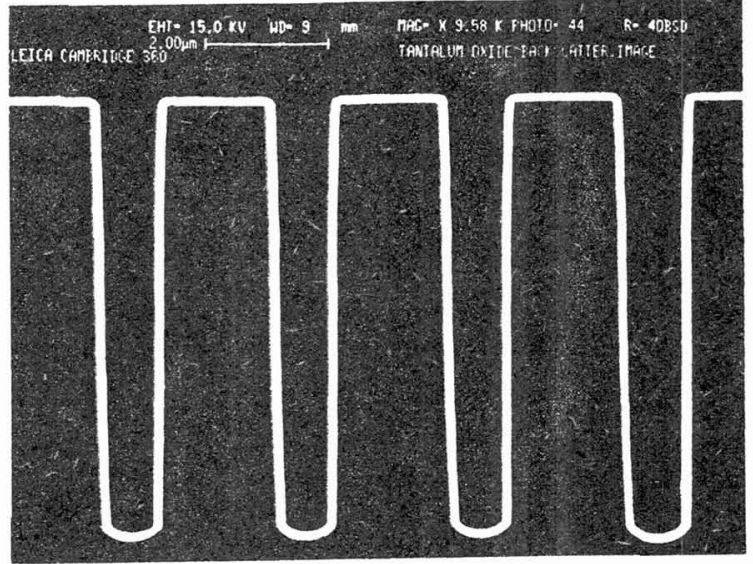

Figure 2. Backscatter image of test sample crosssection showing uniform and conformal coverage of deep trenches in silicon with LPCVD Ta2O5. The scale indicates a dimension of $2.00 \mu \mathrm{m}$.

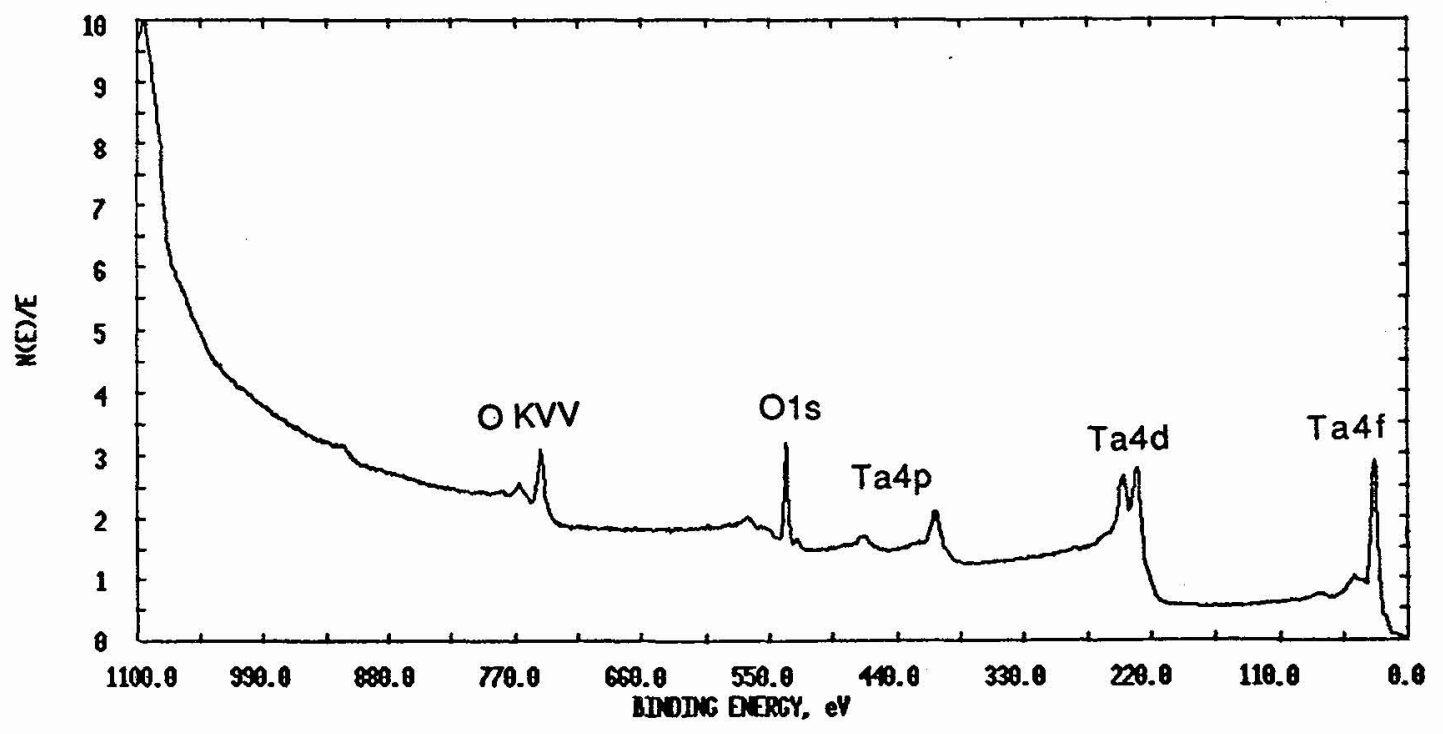

Figure 3. ESCA survey spectrum of a typical $\mathrm{Ta}_{2} \mathrm{O}_{5}$ film deposited at $470^{\circ} \mathrm{C}$. 


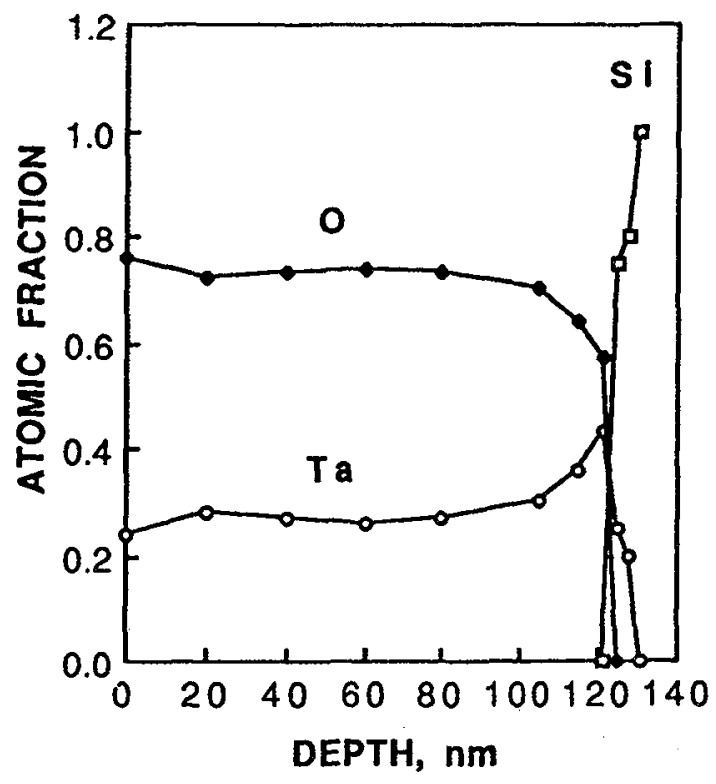

Figure 4. RBS spectrum of Ta2O5 on Si showing a thin interface mixed region containing $\mathrm{Ta}, \mathrm{Si}$, and $\mathrm{O}$.

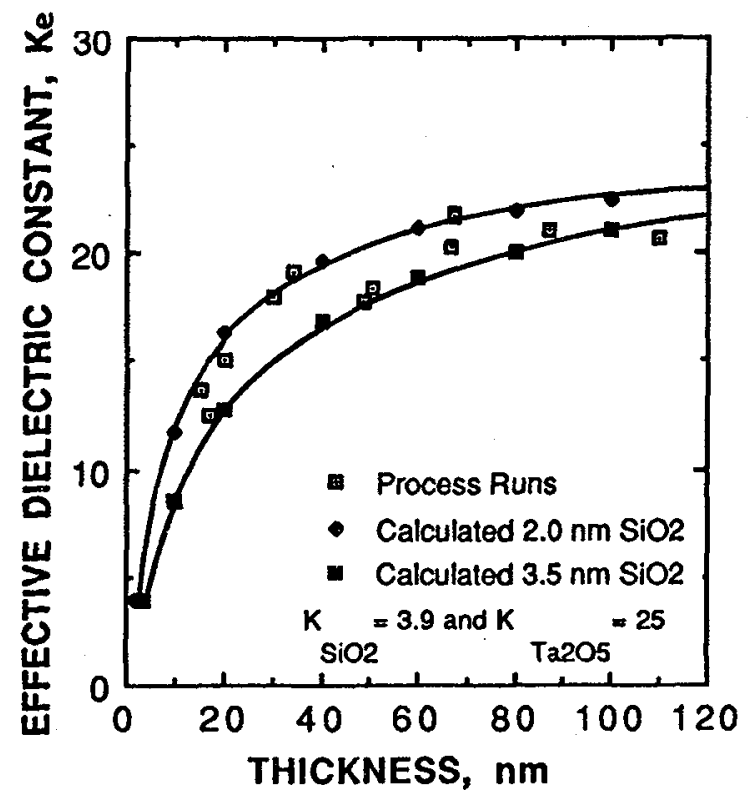

Figure 6. Dependence of effective dielectric constant on film thickness for as-deposited Ta2O5. Calculated values based on $2.0 \mathrm{~nm}$ and $3.5 \mathrm{~nm}$ of $\mathrm{SiO} 2$ interlayer are shown for comparison.

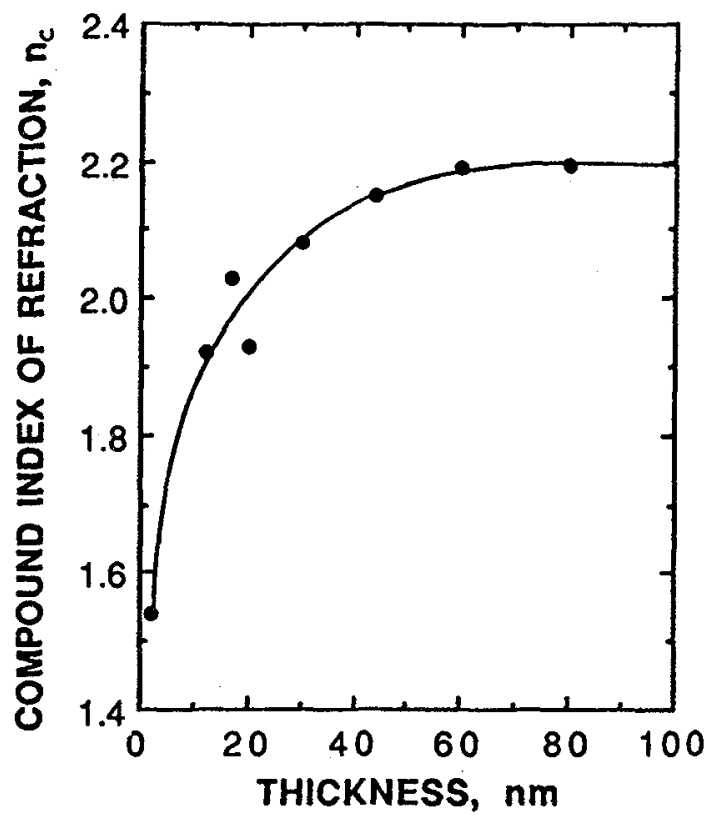

Figure 5. Dependence of compound index of refraction on film thickness.

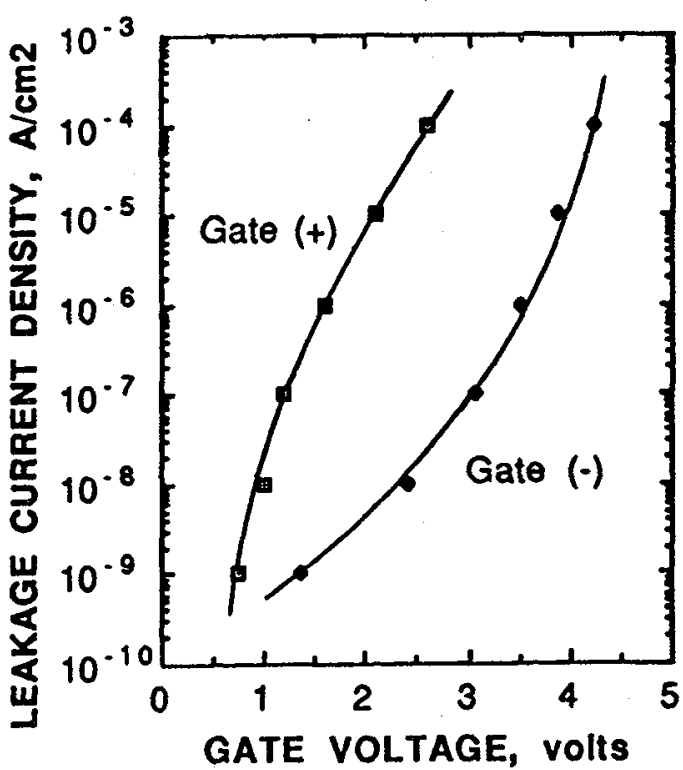

Figure 7. Leakage current density vs gate vollage for MOS capacilors fabricated from a Ta2O5 film annealed for $10 \mathrm{~min}$ at $800^{\circ} \mathrm{C}$ in dry $\mathrm{O}$. 